\title{
BM] Global Health The costs of diabetes treatment in low- and middle-income countries: a systematic review
}

\author{
Corrina Moucheraud, ${ }^{\oplus 1}$ Cosima Lenz, ${ }^{1}$ Michaella Latkovic, ${ }^{2}$ Veronika J Wirtz ${ }^{2}$
}

To cite: Moucheraud C, Lenz C, Latkovic M, et al. The costs of diabetes treatment in low- and middle-income countries: a systematic review. BMJ Glob Health 2019;4:e001258. doi:10.1136/ bmjgh-2018-001258

Handling editor Seye Abimbola

- Additional material is published online only. To view please visit the journal online (http://dx.doi.org/10.1136/ bmjgh-2018-001258).

Received 25 October 2018 Revised 4 January 2019 Accepted 12 January 2019

\section{Check for updates}

(c) Author(s) (or their employer(s)) 2019. Re-use permitted under CC BY-NC. No commercial re-use. See rights and permissions. Published by BMJ.

${ }^{1}$ Health Policy and Management University of California Fielding School of Public Health, Los Angeles, California, USA ${ }^{2}$ Department of Global Health, Boston University School of Public Health, Boston, Massachusetts, USA

Correspondence to Dr Corrina Moucheraud; cmoucheraud@ucla.edu

\section{ABSTRACT}

Introduction The rising burden of diabetes in low- and middle-income countries may cause financial strain on individuals and health systems. This paper presents a systematic review of direct medical costs for diabetes (types 1 and 2) in low- and middle-income countries. Methods Following Preferred Reporting Items for Systematic Reviews and Meta-Analyses guidelines, databases (PubMed, International Bibliography of Social Science, EconLit) were searched for publications reporting direct medical costs of type 1 and 2 diabetes. Data were extracted from all peer-reviewed papers meeting inclusion criteria, and were standardised into per-patient-visit, perpatient-year and/or per-complication-case costs (2016 US\$).

Results The search yielded 584 abstracts, and 52 publications were included in the analysis. Most articles were from Asia and Latin America, and most focused on type 2 diabetes. Per-visit outpatient costs ranged from under $\$ 5$ to over $\$ 40$ (median: $\$ 7$ ); annual inpatient costs ranged from approximately $\$ 10$ to over $\$ 1000$ (median: $\$ 290)$; annual laboratory costs ranged from under $\$ 5$ to over \$100 (median: \$25); and annual medication costs ranged from $\$ 15$ to over $\$ 500$ (median: $\$ 177$ ), with particularly wide variation found for insulin. Care for complications was generally high-cost, but varied widely across countries and complication types.

Conclusion This review identified substantial variation in diabetes treatment costs; some heterogeneity could be mitigated through improved methods for collecting, analysing and reporting data. Diabetes is a costly disease to manage in low- and middle-income countriesand should be a priority for the global health community seeking to achieve Universal Health Coverage.

\section{INTRODUCTION}

Diabetes affects approximately 422 million adults worldwide, ${ }^{1}$ and by 2035 , approximately 592 million people worldwide will live with diabetes. ${ }^{2}$ Increases in the number of people living with diabetes have been, and will continue to be, fastest in low/middle-income countries. ${ }^{12}$ Experts have predicted that it is extremely unlikely that the global community will meet the 2011 United Nations High-Level Meeting on Non-Communicable Diseases

\section{Key questions}

What is already known?

- Valid and reliable estimates of diabetes cost of illness in lower-resource settings are necessary for developing policies and programmes to achieve Universa Health Coverage and treatment for non-communicable diseases worldwide.

\section{What are the new findings?}

- We found that diabetes is a costly disease to manage in low/middle-income countries, which is burdensome for the most vulnerable populations.

- We also found wide variation in reported treatment costs, indicating opportunities for savings.

\section{What do the new findings imply?}

- Policymakers and other global stakeholders should seek ways to reduce the economic burden of this very prevalent disease-particularly costs related to medications and inpatient care to manage complications.

- Additionally, efforts should be made to harmonise or standardise the collection and reporting of cost of illness data.

goal to halt increases in adult prevalence of diabetes by $2025 .{ }^{3}$

In addition to morbidity and mortality, diabetes causes substantial economic burden for individuals, households and health systems ${ }^{14-6}$ : the annual cost of diabetes treatment has been estimated to be as high as US $\$ 825$ billion. $^{3}$ A recent analysis in sub-Saharan Africa estimated that the cost of diabetes in that region is equivalent to $1.2 \%$ of cumulative gross domestic product (or US $\$ 19.5$ billion), and will rise to US\$35US $\$ 59$ billion by $2030 .^{7}$ Particularly in low/ middle-income countries, diabetes treatment costs are primarily borne by individuals via out-of-pocket payments, ${ }^{457}$ which can cause significant financial hardship. ${ }^{89}$

As countries move towards Universal Health Coverage, robust estimates of diabetes treatment costs can be used to forecast 
financial needs at the global and national levels. A recent Lancet Commission on Essential Medicines included a global estimate of financing needed for essential medicines within the context of Universal Health Coverage. ${ }^{10}$ Such estimates are needed for specific diseases, and should include comprehensive treatment costs (beyond only medicines). Estimates of overall costs of diabetes management have been published previously as noted above and elsewhere, ${ }^{11}$ but there remains a gap in our understanding of the specific categories of diabetes treatment costs in low/middle-income countries.

Recent efforts to calculate cost of illness for diabetes have used estimation (modelling) methods. This analysis presents the first-ever systematic review about direct treatment costs of diabetes (types 1 and 2) in low/ middle-income countries, in order to inform such estimates. Specifically, it aims to fill a gap in the literature by providing data on specific categories of treatment costs, and distinguishing between data sources/collection methods, in order to generate more nuanced estimates and thereby inform more specific policy recommendations around financing and providing treatment for diabetes in low/middle-income countries. This review is part of the Addressing the Challenge and Constraints of Insulin Sources and Supply (ACCISS) study, which aims to generate new evidence and synthesise knowledge about type 1 and 2 diabetes.

\section{METHODS \\ Literature search}

We followed the Preferred Reporting Items for Systematic Reviews and Meta-Analyses guidelines using a keyword search for papers published since 2007 in PubMed, International Bibliography of Social Science and EconLit databases. (See search details in online supplementary appendix 1.) The searches were conducted in January andFebruary 2017. No language restriction was applied. Each author reviewed a set of abstracts, and determined relevance based on inclusion criteria, which were: data collected from low/middle-income countries (using World Bank grouping), ${ }^{12}$ cost data collected in or since 2007 (to include only recent data which might be more meaningful and comparable), article subject was diabetes (types 1 and/or 2), and article was an empirical analysis based on economic data. Only primary data were included (ie, modelled analyses, including cost-effectiveness analyses and other cost simulations, were excluded) in order to estimate real-world 'cost of illness' results that would reflect actual economic values and could inform decision-making by policymakers and practitioners. All abstracts were imported into EndNote and duplicates were removed. Full texts were retrieved for publications that met the inclusion criteria.

At this second stage, publications in languages other than English, Spanish, Portuguese, French, German, Russian, Serbian and Chinese were excluded. Additionally, reviews, editorials, commentaries and opinion pieces (all non-peer-reviewed publications) were excluded. Lastly, papers that provided only abstracts or vague reporting of methods or results, non-rigorous sampling design, unsuitable outcome definitions or severe methodological limitations in their statistical analyses were also excluded. The full search protocol is available from the corresponding author on request.

\section{Data extraction}

A data extraction sheet was developed and piloted. CL and ML extracted data from each eligible publication: geographic location, study population, study sites, information about costing method and reported costs in categories as available (hospital care, outpatient consultation, complication care, medicines, monitoring supplies and diagnostics/laboratory tests). If a study did not provide enough information to judge its methodological rigour, it was excluded. If the data were unclear or were not presented in a format corresponding to this analysis, the authors were contacted for additional details. (In two such cases, the authors indicated that these data were available in an article that was published after the literature search, so these were manually added to the database.) Information was also abstracted about each study's source of funding.

\section{Data analysis}

Studies were classified according to geographic region, country income group per 2018 fiscal year classifications (low-income country (LIC), lower middle-income country (LMIC), upper middle-income country (UMIC)), ${ }^{12}$ year of publication and data collection methods, which were distinguished as: directly from patients (ie, using surveys or interviews), from a provider/system perspective (ie, gleaned from health facility or insurance records) and a hybrid approach that combined these methods. Each of these three data sources is necessarily incomplete: that is, total direct medical costs are likely to include patient costs, provider costs and other societal costs. Additionally, articles were analysed for data contributing to the main analysis, and/or to a subgroup analysis about care for diabetic complications. Only some studies reported on these additional specific costs, and since the data were not comparable across articles, these were not included in the main results but rather as subgroups.

Data were standardised to annual per-patient costs attributable to diabetes, and diabetes-related complication costs which were expressed as per-case. Outpatient costs were also presented as per-visit costs when reported. Eligible outpatient data included only clinician/provider and consultation fees related to the visit; medicines, laboratory tests, supplies or other service-related costs were reported separately. If a study did not provide data with sufficient granularity, or methods with sufficient information to assess sources and risks of bias, these data were not included in the main comparative analysis. The authors discussed all studies that were conducted among special subpopulations (those not necessarily generalisable to 


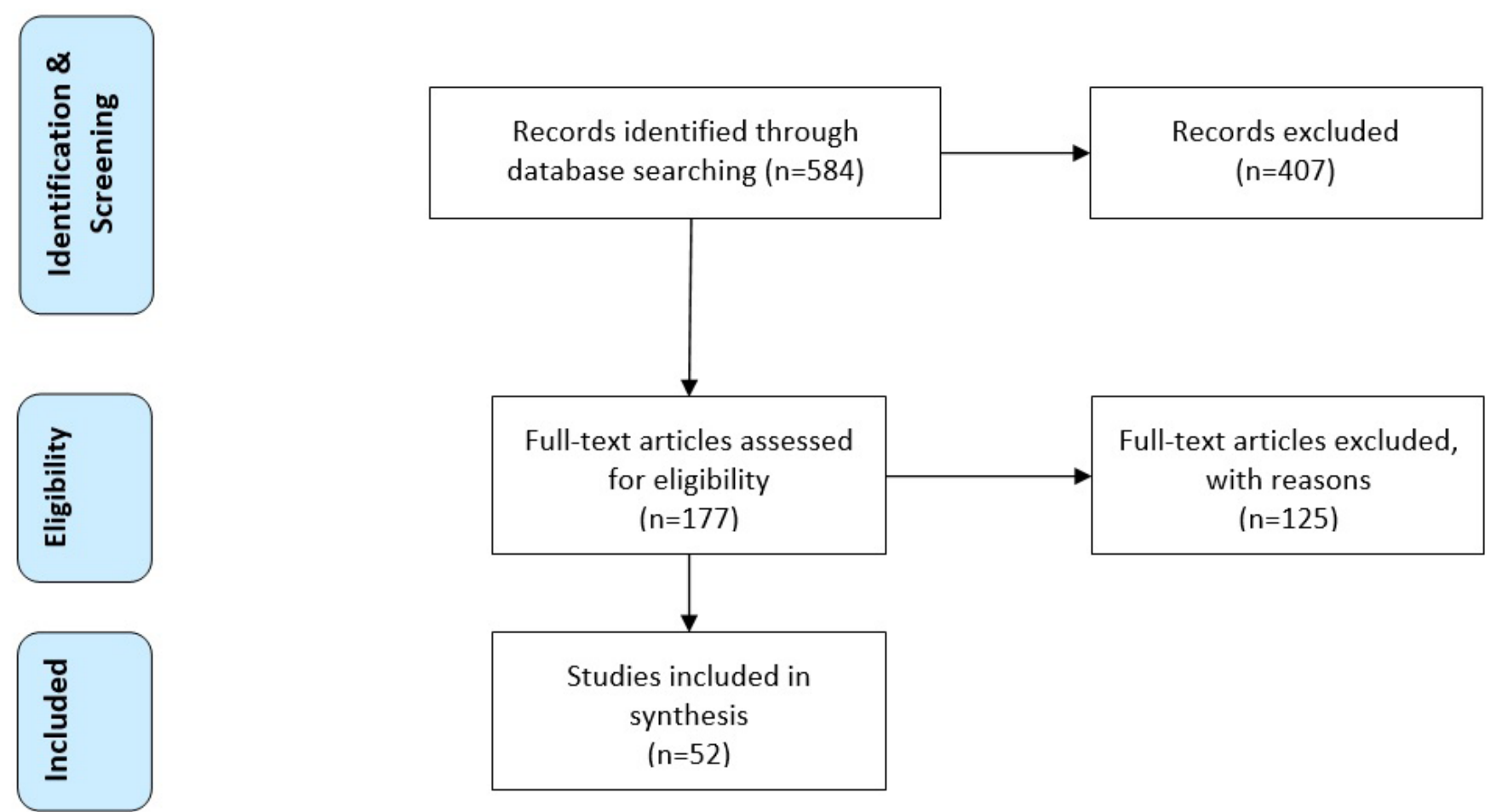

Figure 1 Flow of abstract and article selection. Note: Articles could be excluded from review for more than one reason.

the population of people with diabetes) to assess potential sample selection bias. Medicine costs include diabetes medicines and any others such as those used to treat related comorbidities. Inpatient costs were also included; these were inclusive of medication and laboratory costs, and were expressed as annual costs per patient. For publications that reported data in local currency, these costs were converted into US $\$$ for the year of data collection using the Federal Reserve Bank exchange rates (1 January of each year). ${ }^{13}$ All costs were adjusted for inflation using the 2016 Consumer Price Index (see online supplementary appendix 2). ${ }^{14}$

\section{RESULTS}

The search strategy yielded 584 unique abstracts to review (figure 1). After title and abstract screening, 177 were selected for full-text screening. Of these, 46 were included in the analysis plus an additional 6 were included in the complications subanalysis (total=52). The main reasons for exclusion were: unavailability of full text (mainly because only an abstract had been published with no full text, many of which were conference presentations $(n=40))$; or if the full text did not meet the inclusion criteria (including data collected prior to 2007 $(n=39)$, not providing primary data, eg, modelled analyses or reviews of secondary data $(n=34)$, or reporting of cost data with insufficient granularity for the categories of this analysis $(n=52)$ ). (Descriptive information about all included articles can be found in online supplementary appendix 3.)

Looking at those articles that provided results for this paper (on cost of illness and/or on diabetes medicines), there has been an overall increasing number of publications over the last decade, with some year-to-year fluctuations. During the period 2013-2016, there were on average 7.5 publications per year, an increase from 3.5 per year in the 2009-2012 period (figure 2). Approximately half of the articles $(n=22,47.8 \%$ of the analysis sample) have used data from Asia (mainly East Asia and the Pacific (figure 3)); there have also been 10 articles (21.7\% of the sample) using information from Latin America and the Caribbean, 6 (13.0\%) from the Middle East/North Africa, 5 from Europe/Central Asia (10.9\%) and 2 from sub-Saharan Africa (4.3\%). In addition, one article $^{15}$ provided information on 13 countries, across regions. Most articles $(29,63.0 \%)$ were from UMICs, 14 $(30.4 \%)$ were from LMICs and $2(4.3 \%)$ were from LICs.

For articles included in the overall cost of illness analyses, all used a bottom-up costing methodology. $41.9 \%$ $(n=13)$ used data reported by patients, 35.5\% $(n=11)$ used data from the provider/system and 7 (22.6\%) incorporated data from both these sources. Many of these articles have been specifically about type 2 diabetes $(n=16$, $51.6 \%)$; only two focused only on type 1 diabetes $(6.5 \%)$. An additional six articles $(19.4 \%)$ were about both types 1 and 2; and for seven articles (22.6\%), the authors did not specify the type of diabetes. Most studies used information collected at specialised care sites, either outpatient clinics or hospitals (including referral hospitals).

For the 13 analyses that collected data directly from patients (using surveys or interviews) (table 1), the average sample size was 922 participants (range: minimum 86, maximum 4500). Nine of these studies were from Asia, one from sub-Saharan Africa, two from 


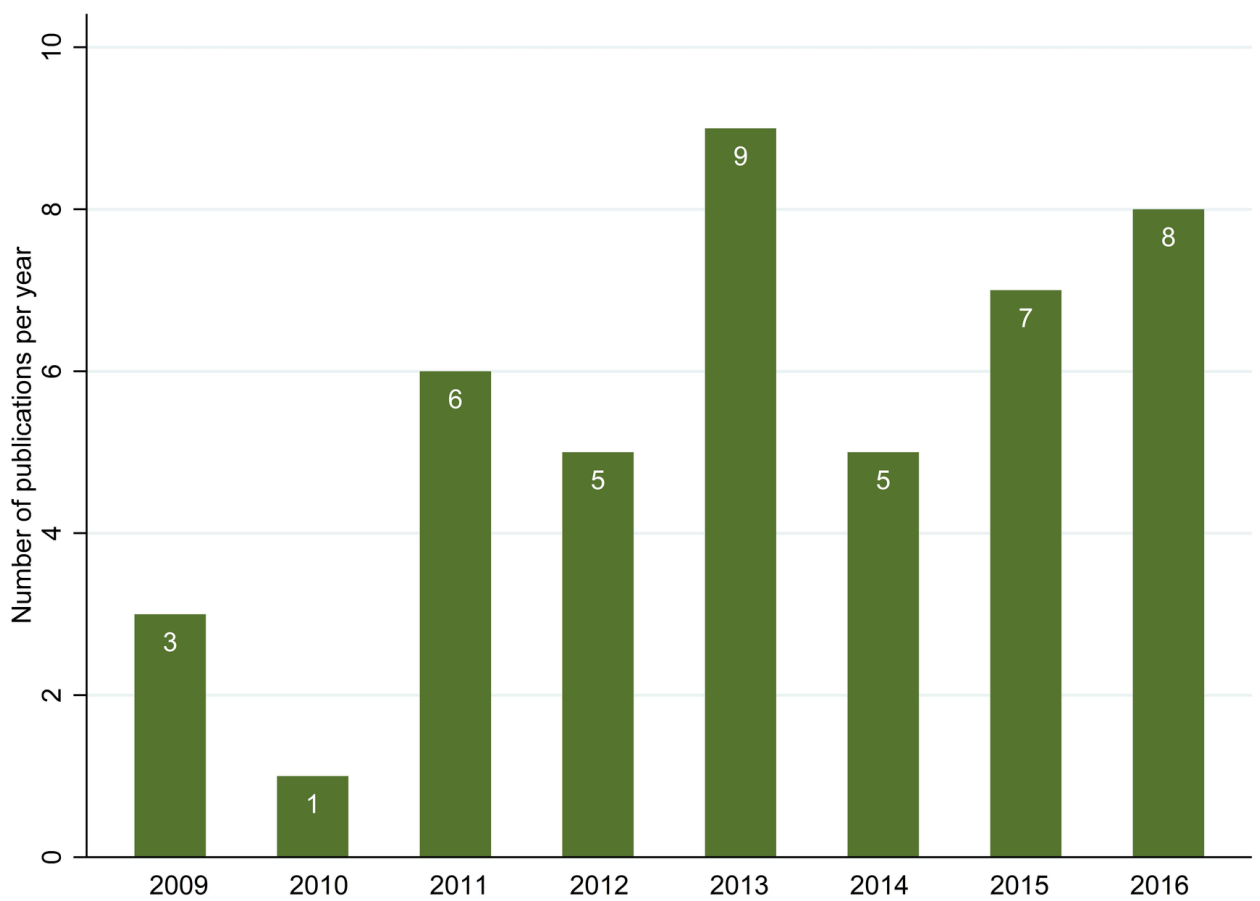

Figure 2 Year of publication for included publications. There were also two articles from 2017 (published subsequent to the search) which were added following author instructions but did not result from the search and so are not presented here.

Europe and Central Asia, and one was from the Middle East. In 12 of these studies, the mean age of participants was approximately 52 years (one study, which was focused on type 1 diabetes, had a mean age of 15 years).

Among these studies with data reported by patients, average per-visit outpatient costs ranged from US $\$ 2.67$ (in the Solomon Islands) to US\$7.41 (in India). Annual outpatient visit costs were reported in two studies in
LMICs (US\$14.82 and US\$14.93, both in India), and in one study in a UMIC (US\$56.94 in Iran). Annual medication costs were on average lower in the group of LICs and LMICs (approximately US $\$ 95$ average per year for this group, median US\$76) than among UMICs (average US\$297 per year in this group, median US\$252). Inpatient costs varied by country but were generally lower for LIC and LMIC (US\$139 per-patient annual average in LICs

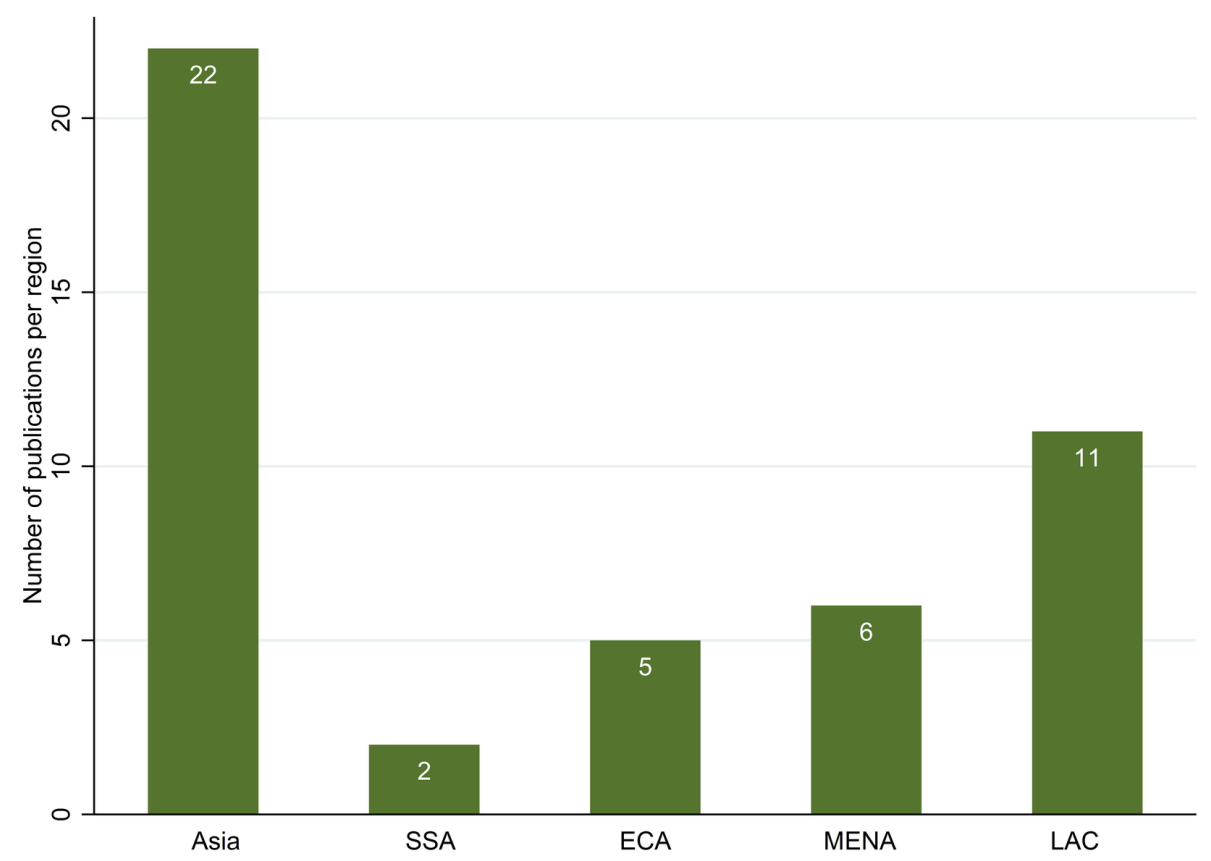

Figure 3 Geographic source of data for included publications. ECA, Europe/Central Asia region; LAC, Latin America/ Caribbean region; MENA, Middle East/North Africa region; SSA, sub-Saharan Africa region. 
Table 1 Cost components from studies based on data reported by patients

\begin{tabular}{|c|c|c|c|c|c|c|c|}
\hline & \multirow[b]{2}{*}{ Country/study } & \multirow[b]{2}{*}{$\begin{array}{l}\text { Diabetes } \\
\text { type }\end{array}$} & \multirow[b]{2}{*}{$\begin{array}{l}\text { Outpatient } \\
\text { (per visit) }\end{array}$} & \multicolumn{4}{|c|}{ Cost components, average per person (2016 US\$) } \\
\hline & & & & $\begin{array}{l}\text { Outpatient } \\
\text { visits } \\
\text { (per year) }\end{array}$ & $\begin{array}{l}\text { Laboratory } \\
\text { (per year) }\end{array}$ & $\begin{array}{l}\text { Medicines } \\
\text { (per year) }\end{array}$ & $\begin{array}{l}\text { Inpatient (per } \\
\text { year) }\end{array}$ \\
\hline \multirow[t]{2}{*}{ LICs $(n=2)$} & $\mathrm{Nepal}^{28}$ & 1 and 2 & 4.39 & * & 31.70 & 77.70 & * \\
\hline & Mali $^{29}$ & Unclear & * & * & * & 55.97 & 281.05 \\
\hline \multirow[t]{6}{*}{ LMICs $(n=6)$} & Kyrgyzstan ${ }^{30}$ & 1 and 2 & * & * & * & 141.65 & 53.43 \\
\hline & India ${ }^{31}$ & Unclear & 7.41 & 14.82 & 24.31 & * & 242.91 \\
\hline & India ${ }^{32}$ & 2 & 6.65 & * & 23.08 & 15.20 & 20.57 \\
\hline & India ${ }^{33}$ & Unclear & * & 14.93 & 16.65 & 74.78 & 18.09 \\
\hline & India ${ }^{34}$ & 1 & * & * & 17.00 & 223.00 & * \\
\hline & $\begin{array}{l}\text { Solomon } \\
\text { Islands }^{35}\end{array}$ & 2 & 2.67 & * & * & 75.76 & 218.73 \\
\hline \multirow[t]{5}{*}{ UMICs $(n=5)$} & $\operatorname{Iran}^{36}$ & 2 & * & 56.94 & 85.02 & 224.42 & 550.86 \\
\hline & China $^{16}$ & 2 & * & * & * & * & 549.13 \\
\hline & China $^{37}$ & Unclear & * & * & * & 257.93 & 414.37 \\
\hline & China $^{38}$ & 2 & * & * & * & 245.78 & 655.45 \\
\hline & Romania ${ }^{39}$ & Unclear & * & 5.44 & * & 459.18 & 8.10 \\
\hline
\end{tabular}

*Authors did not provide data on this cost component.

LIC, low-income country; LMIC, lower middle-income country.

and LMICs, median US\$136) than in UMIC (US\$436, median US\$549). Laboratory costs were approximately $\$ 33$ per person per year on average (median US\$24).

Among studies that took a provider/system perspective, the average outpatient per-visit cost was approximately US\$17 (median US\$11) (table 2). Annual medication costs were US $\$ 216$ on average (median $\$ 91$ ), and average annual inpatient costs were US\$709 (median US\$680). Laboratory costs were approximately US $\$ 42$ per year on average (median US\$24). There were not enough data points from LMICs to make any meaningful comparisons between income groups.

In articles that used data both from patient interviews and from the provider/system perspective, per-visit outpatient costs and medicine costs were US $\$ 19$ and US $\$ 460$ (median US\$13 and US $\$ 494$, respectively); and inpatient costs were US\$530 on average (median US\$464) (table 3). Average annual per-person laboratory costs were US\$98 (median US\$78). There were not enough data points from LMICs to make any meaningful group comparisons.

Table 2 Cost components from studies based on data from provider/system perspective

\begin{tabular}{|c|c|c|c|c|c|c|c|}
\hline & \multirow[b]{2}{*}{ Country/study } & \multirow[b]{2}{*}{$\begin{array}{l}\text { Diabetes } \\
\text { type }\end{array}$} & \multirow[b]{2}{*}{$\begin{array}{l}\text { Outpatient } \\
\text { (per visit) }\end{array}$} & \multicolumn{4}{|c|}{ Cost components, average per person (2016 US\$) } \\
\hline & & & & $\begin{array}{l}\text { Outpatient } \\
\text { visits } \\
\text { (per year) }\end{array}$ & $\begin{array}{l}\text { Laboratory } \\
\text { (per year) }\end{array}$ & $\begin{array}{l}\text { Medicines } \\
\text { (per year) }\end{array}$ & $\begin{array}{l}\text { Inpatient (per } \\
\text { year) }\end{array}$ \\
\hline LMICs $(n=1)$ & Bangladesh $^{40}$ & 2 & * & 24.00 & 27.00 & 194.00 & \\
\hline \multirow[t]{10}{*}{ UMICs $(n=10)$} & $\operatorname{Iran}^{41}$ & 2 & * & * & 4.72 & * & * \\
\hline & Thailand ${ }^{42}$ & 1 and 2 & 3.99 & 18.09 & 14.74 & 26.41 & 24.95 \\
\hline & China $^{43}$ & 1 and 2 & * & * & * & * & 990.79 \\
\hline & China $^{44}$ & & * & * & * & * & 1790.22 \\
\hline & Mexico ${ }^{45}$ & 2 & 10.75 & 84.81 & * & 73.07 & * \\
\hline & Mexico $^{46}$ & 2 & 42.32 & 173.29 & 24.13 & * & * \\
\hline & Brazill $^{47}$ & 2 & 4.75 & 8.66 & 16.16 & 91.30 & * \\
\hline & Brazill $^{48}$ & 1 & * & * & 56.93 & 415.47 & 29.44 \\
\hline & Turkey ${ }^{49}$ & 2 & * & * & * & 668.41 & * \\
\hline & Argentina $^{50}$ & 1 and 2 & 21.74 & & 152.43 & 40.06 & 679.60 \\
\hline
\end{tabular}

*Authors did not provide data on this cost component.

LMIC, lower middle-income country; UMIC, upper middle-income country. 
Table 3 Cost components from studies based on data from both patient and provider/system perspectives (mixed)

(1)

*Authors did not provide data on this cost component.

LMIC, lower middle-income country; UMIC, upper middle-income country.

Figure 4 displays the annual diabetes care cost components-inpatient care, medicines and laboratory services-for all articles included in this review. This graph displays per-article information, grouped by data source and in ascending order of per-capita gross domestic product within each group. (As not all articles provided information on all cost components, low bars may reflect low prices and/or unavailable data.) Medicines were the most common cost component reported in these articles (in 24 articles, or $77 \%$ of the sample), followed by inpatient costs (20 articles, 65\%) and laboratory costs (17 articles, 58\%). Fewer than half of studies reported on outpatient costs (whether annual or per visit). On average, articles included 2.6 cost components; only eight articles included all four components.

Figure 5 presents per-visit outpatient costs for studies that provided this information. Articles from China have the highest reported per-visit outpatient costs, followed by other UMICs such as Mexico and Argentina. The lowest per-visit outpatient costs were in LICs and LMICs.

Online supplementary appendix 4 presents information about the cost of managing diabetes-related

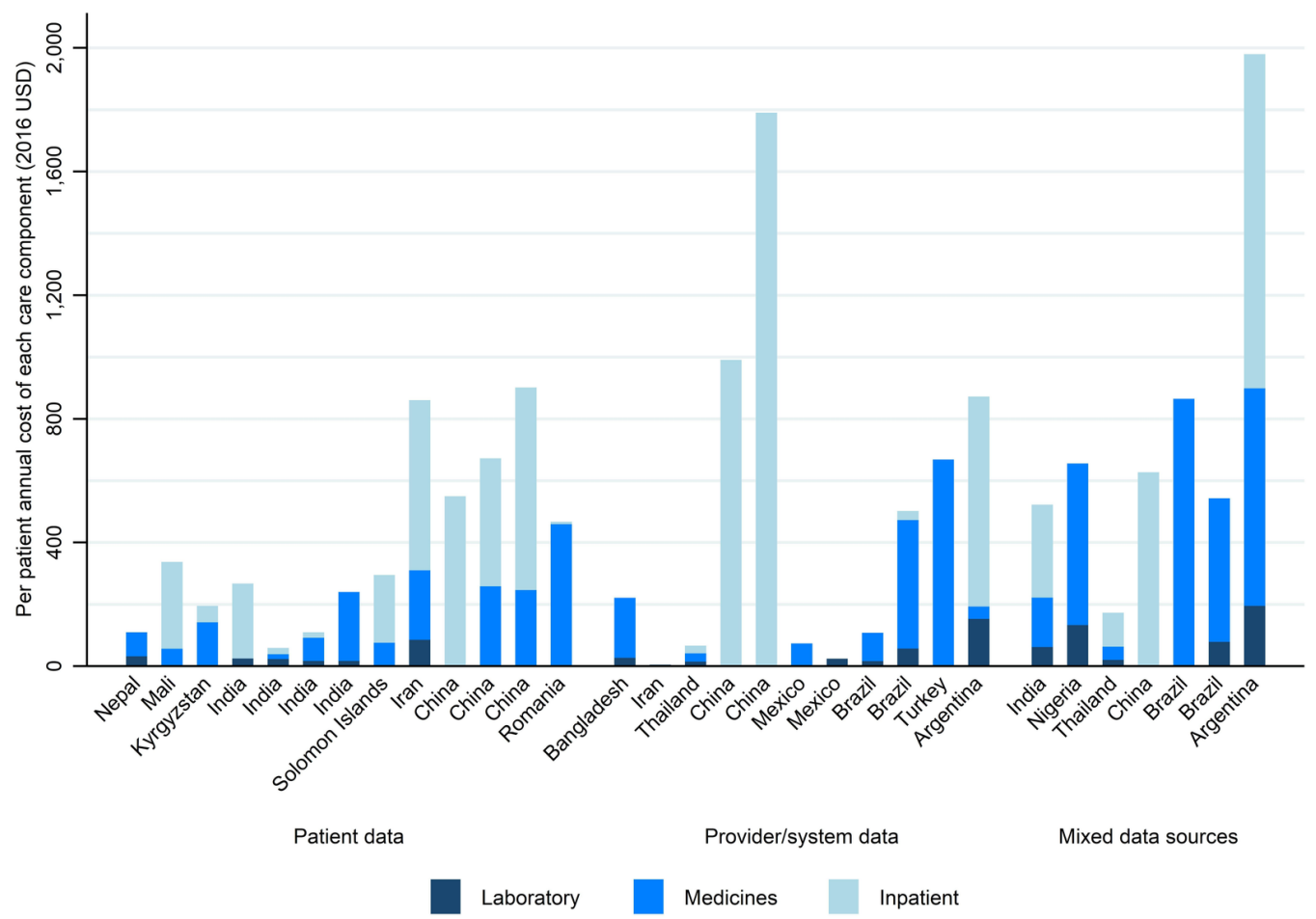

Figure 4 Per-patient annual costs of diabetes care components (among articles reporting on these components). Note: Articles are organised first within data collection-type groups; and within each of these, in ascending order of per-capita gross domestic product. 


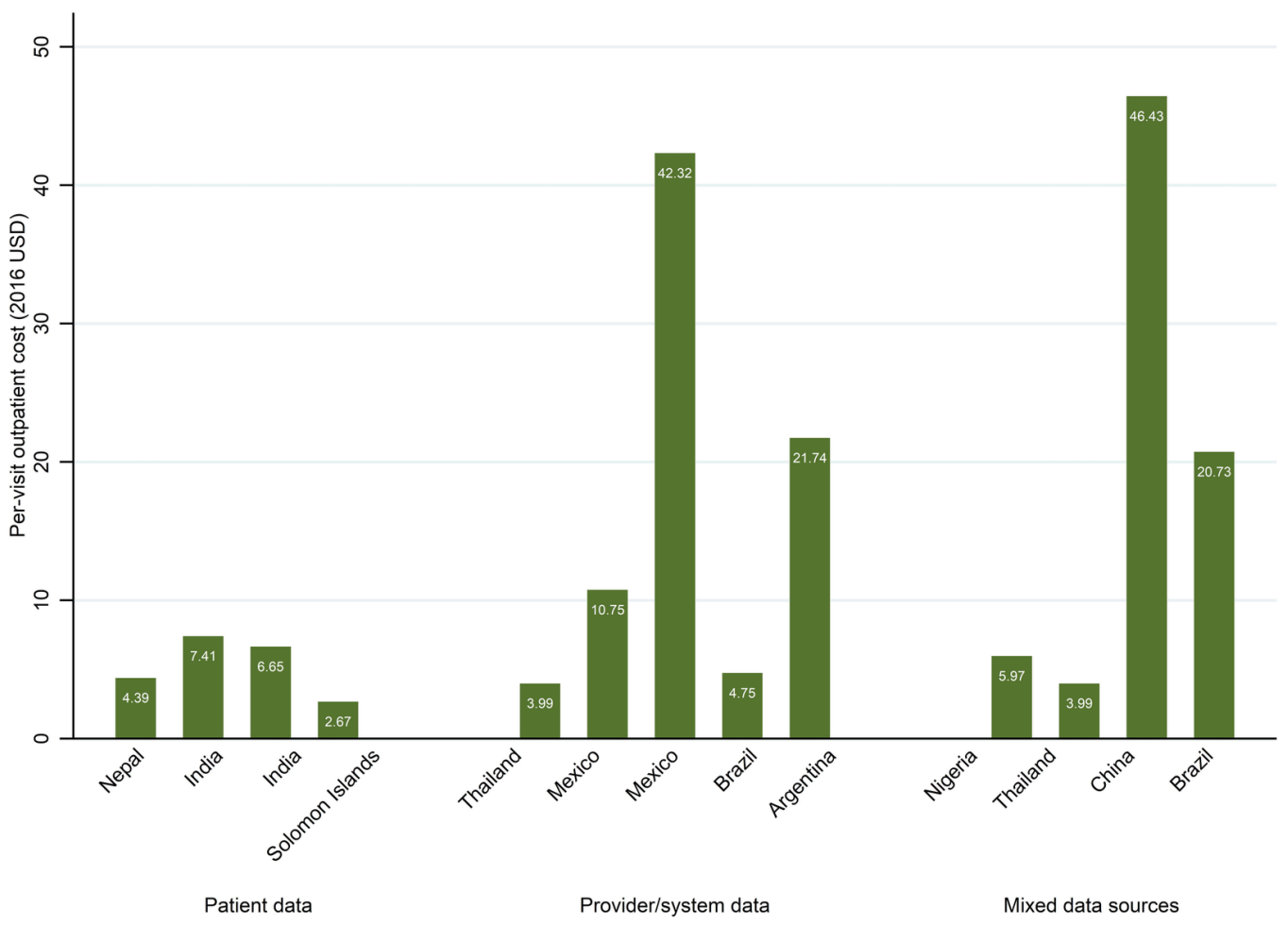

Figure 5 Per-visit outpatient visit costs of diabetes (among articles reporting on this). Note: Articles are organised first within data collection-type groups; and within each of these, in ascending order of per-capita gross domestic product. Outpatient visit costs include provider and consultation fees, as applicable.

complications. Some articles grouped all complications together while others specified costs per type of complication. In studies from China and Colombia, ${ }^{16}{ }^{17}$ the most expensive complications included cardiovascular conditions and events (approximately US $\$ 2000$ per patient per year to manage). There was considerable heterogeneity across these articles: the annual cost of managing cataracts was estimated to be US $\$ 1500$ in China (one of the most expensive complications in that analysis), ${ }^{16}$ but under US\$200 in Thailand. ${ }^{18}$

Table 4 presents information from articles that provided data on diabetes medication costs, per year. The most common medication in these analyses was insulin, and the cost of this varied widely across publications, from under US\$60 per year in Pakistan, the Solomon Islands, Brazil and Serbia; to more than US $\$ 300$ in Central African Republic, Brazil, India, Malawi, Bulgaria and Jordan. Notably, these highest costs were for treating type 1 diabetes. Among articles about type 2 only, insulin generally cost around US $\$ 50-$ US $\$ 100$ per patient per year. Several articles also mentioned prices for metformin, and again there was a large range, from approximately US $\$ 25$ per patient per year in Cambodia, to over US\$200 in China and Argentina.

\section{DISCUSSION}

This systematic review identified 31 articles with information on the cost of care for diabetes, plus an additional
15 articles focused on per-medicine costs only. Half of the comprehensive cost of illness papers were based on data from Asia, and another quarter were from Latin America; data from UMICs constituted nearly two-thirds of the sample. Type 2 diabetes was the sole or main focus in the majority of articles. These gaps suggest areas of opportunity for future research-for example, on the costs of type 1 diabetes care, and on cost of illness in geographic regions that have been under-represented in this literature to date including sub-Saharan Africa, the Middle East/North Africa and Europe/Central Asia.

These results indicate that diabetes care may be very expensive for patients in low/middle-income countries. Since many individuals worldwide lack health insurance, out-of-pocket payments for diabetes treatment may pose large financial burden on these households. This highlights the importance of identifying approaches to reduce these expenses-including treatment cost reduction strategies, and further investments in prevention to reduce the number and severity of high-cost complications. It is estimated that approximately 800 million people spend at least one-tenth of their annual household budget on health-related expenses; out of these, one in eight households is forced to live on US $\$ 1.90$ or less per day as a result. ${ }^{19}$ This study was unable to investigate affordability or the relationship between reported care costs and household income, but other studies have found important linkages between these ${ }^{20}{ }^{21}$-which 


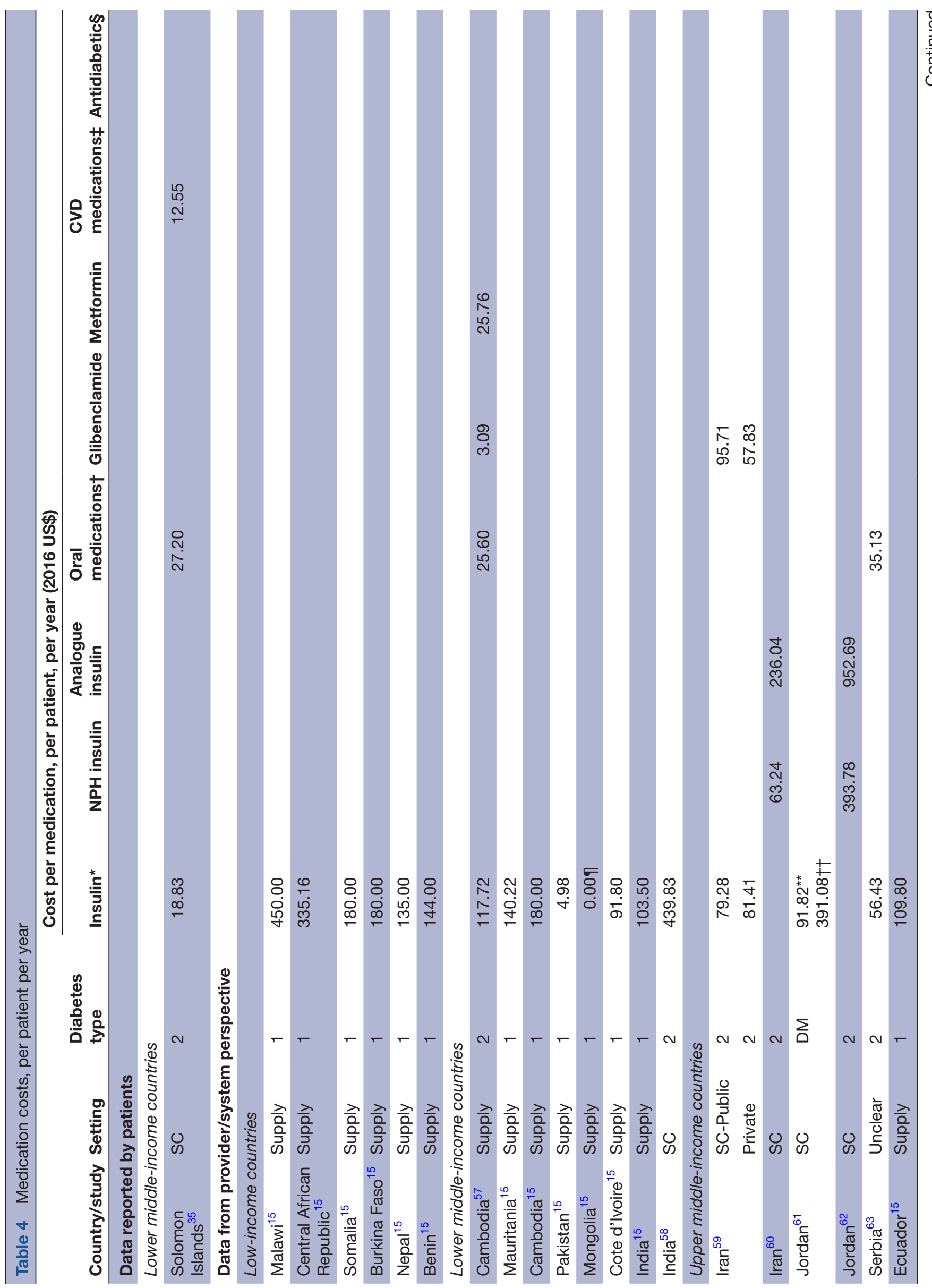




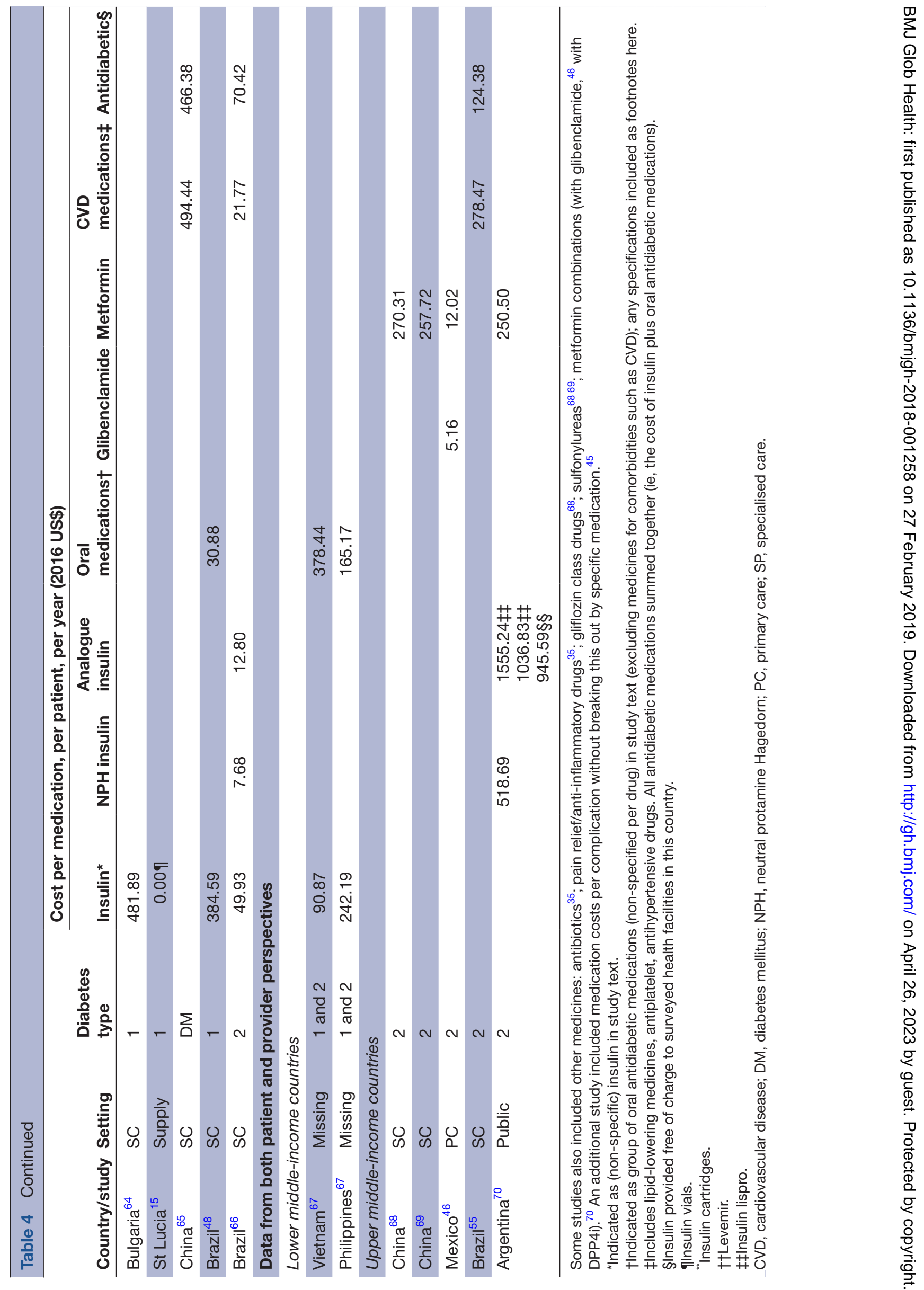


suggests the need for future research to explore issues of affordability for both patients and systems coping with chronic diseases including diabetes. Additionally, the concept of affordability should be explored in the context of health system structure, and the potential role of governments and other system financers in managing treatment costs-and governments should be encouraged to provide information on costs (to patients and to insurance plans) and procurement prices for diabetes care.

Annual inpatient and medication costs were found to be the most expensive aspects of diabetes care in studies that reported on these. Of particular note is the very high cost of insulin, particularly for treating type 1 diabetes. Diabetes care also requires frequent laboratory tests, which carries substantial costs according to this analysis: the median annual value was US $\$ 25$, and this ranged from below US $\$ 5$ to almost US $\$ 200$. Additionally, although only a few studies reported costs of clinical supplies apart from medication, the available data suggest that supplies also may contribute considerable expense.

There was also a high degree of cost variability: some studies reported annual inpatient costs below $\$ 20$ while others were over $\$ 1000$, and medicines ranged from below $\$ 20$ per year to over $\$ 500$. Outpatient costs were, at the median, $\$ 7$ per visit and this also varied widely (from under $\$ 3$ to almost $\$ 50$ ). Large cost variations were reported between and within countries, possibly due to care utilisation at different levels of the health system or from different sectors. Due to the wide variation in costs and methodologies, comparisons across studies should be taken with caution.

The review included studies that used different methodologies for data collection. The results of these methods are not directly comparable: for example, insurance companies may see very different costs than someone paying out of pocket. Patient-reported data may also contain selection and recall bias. Articles using mixed methodologies for cost data collection may therefore offer the most complete picture of treatment costs, as this method would include multiple salient perspectives. This review also included articles that reported on diabetes types 1 and 2 (and some reported on both, without differentiation, while others did not specify the type of diabetes under study). Given the very different treatment protocols for diabetes types 1 and 2, future research should make this distinction more clearly.

A limitation of this analysis is the heterogeneity in data reporting among articles included here; previous reviews have similarly noted this limitation. ${ }^{22}$ Some papers do not specify important methodological details, such as year of data collection, sample selection (including clear inclusion and exclusion criteria, which makes it challenging to ascertain the generalisability of the results) and participant recruitment. Currency information is particularly problematic, as some articles do not clearly denote which currency (including currency year) was used for their results. This highlights the need for standardised data collection and reporting, based on best practices from the health economics literature, including specifying currency units, years of data collection and years of currency; using clear terminology on type of costing methodology used; and stratifying costs by meaningful categories (eg, reporting on supplies separately from medicines and laboratory costs). There are published best practices for generating and reviewing cost-of-illness studies, which could guide such efforts to strengthen and align methodological approaches ${ }^{22} 23$; and examples from other disease areas, such as HIV, may offer a useful model for the field of non-communicable disease treatment cost reporting. ${ }^{24}{ }^{25}$ Additionally, authors of cost-of-illness studies for diabetes should be encouraged to report both average and median costs (currently very few do); and to report costs for all relevant units of time, whether per visit, per month or per year. Lastly, for treatment components that may not be used by all patients every year-for example, inpatient care-authors should specify whether these costs are reported only among the subgroup of utilisers, oraveraged out across the full sampled population including non-users.

Despite these limitations, this study adds to the evidence base on diabetes treatment costs. Previous studies have included modelled estimates, ${ }^{112627}$ and this empirical information on treatment costs will help close data gaps that are essential for improving future estimates.

\section{CONCLUSION}

The body of literature on cost of treatment for people with diabetes in low/middle-income countries has been growing. Most of these publications are from UMICs in Asia and Latin America, and focus on type 2 diabetes. Although methods vary widely, the data suggest that diabetes is an expensive disease to manage. There is also a need for greater standardisation in the methods of collecting, analysing and reporting data on the cost of treating diabetes. Based on this analysis, the costs of managing this illness-which represents an increasing burden of disease in low/middle-income countries-are substantial. Improved data would be of enormous use to policymakers, clinicians, academics and civil society worldwide.

Acknowledgements The authors thank Marg Ewen, David Beran, Hans Hogerzeil and Richard Laing from the ACCISS study for their valuable comments on earlier drafts of this paper.

Contributors CM and VJW conceived the study, developed the research protoco and all data collection instruments, and led data collection and analysis. CL and $\mathrm{ML}$ participated in data collection and analysis. CM wrote the first draft of the manuscript with substantial input from VJW, and all authors provided feedback and edits. All authors approved of the final version for publication.

Funding The Leona M and Harry B Helmsley Charitable Trust and Stichting ICF funded the ACCISS study.

Disclaimer The analysis in this paper is that of the authors alone and does not necessarily reflect the views of the Helmsley Charitable Trust or Stichting ICF. All references and conclusions are intended for educational and informative purposes and do not constitute an endorsement or recommendation from the Helmsley Charitable Trust or Stichting ICF. 
Competing interests VJW is coinvestigator of the Evaluation of Access Accelerated, an initiative that seeks to increase access to non-communicable disease treatments in low/middle-income countries. Her institution is receiving a grant to study the effects of this initiative. However, the publications of the results are not subject to control by the funding organisation, IFPMA (see also agreement http://sites.bu.edu/evaluatingaccessaccessaccelerated/agreements/). VJW is also co-PI of the study of Evaluation of Novartis Access, a programme that seeks to increase access to non-communicable diseases treatment in low/middleincome countries. Her institution is receiving a grant to study the effects of this programme. However, the publications of the results are not subject to control by the funding organisation, Sandoz International (see also agreement http://sites.bu. edu/novartisaccessevaluation/agreements/).

Patient consent for publication Not required.

Provenance and peer review Not commissioned; externally peer reviewed.

Data sharing statement № additional data are available.

Open access This is an open access article distributed in accordance with the Creative Commons Attribution Non Commercial (CC BY-NC 4.0) license, which permits others to distribute, remix, adapt, build upon this work non-commercially, and license their derivative works on different terms, provided the original work is properly cited, appropriate credit is given, any changes made indicated, and the use is non-commercial. See: http://creativecommons.org/licenses/by-nc/4.0/.

\section{REFERENCES}

1. World Health Organization. Global report on diabetes. Geneva: World Health Organization, 2016.

2. Guariguata L, Whiting DR, Hambleton I, et al. Global estimates of diabetes prevalence for 2013 and projections for 2035. Diabetes Res Clin Pract 2014:103:137-49.

3. NCD Risk Factor Collaboration. Worldwide trends in diabetes since 1980: a pooled analysis of 751 population-based studies with $4 \cdot 4$ million participants. The Lancet 2016;387:1513-30.

4. Seuring T, Archangelidi O, Suhrcke M. The economic costs of type 2 diabetes: a global systematic review. Pharmacoeconomics 2015;33:811-31.

5. Ettaro L, Songer TJ, Zhang P, et al. Cost-of-illness studies in diabetes mellitus. Pharmacoeconomics 2004:22:149-64.

6. Ng CS, Lee JY, Toh MP, et al. Cost-of-illness studies of diabetes mellitus: a systematic review. Diabetes Res Clin Pract 2014:105:151-63

7. Atun R, Davies JI, Gale EAM, et al. Diabetes in sub-Saharan Africa: from clinical care to health policy. Lancet Diabetes Endocrinol 2017:5:622-67.

8. Xu K, Evans DB, Kawabata K, et al. Household catastrophic health expenditure: a multicountry analysis. The Lancet 2003;362:111-7.

9. Bloom DE, Chatterii S, Kowal P, et al. Macroeconomic implications of population ageing and selected policy responses. The Lancet 2015;385:649-57.

10. Wirtz VJ, Hogerzeil HV, Gray AL, et al. Essential medicines for universal health coverage. The Lancet 2017;389:403-76.

11. Bommer C, Heesemann E, Sagalova V, et al. The global economic burden of diabetes in adults aged 20-79 years: a cost-of-illness study. Lancet Diabetes Endocrinol 2017;5:423-30.

12. World Bank. Country and lending groups, 2017. Available: http:// data.worldbank.org/about/country-and-lending-groups

13. Federal Reserve Bank. FedGlobal foreign exchange rate calculator, 2017. Available: https://www.frbservices.org/app/fedachfx/rateCalc ulationRequest.action

14. Federal Reserve Bank. Consumer price indexes (Cpl and PCE), 2017. Available: https://fred.stlouisfed.org/categories/9

15. Ogle GD, Kim H, Middlehurst AC, et al. Financial costs for families of children with type 1 diabetes in lower-income countries. Diabetic Medicine 2016;33:820-6.

16. Wang W, McGreevey WP, Fu C, et al. Type 2 diabetes mellitus in China: a preventable economic burden. Am J Manag Care 2009;15:593-601.

17. Chicaíza-Becerra LA, Gamboa-Garay O, García-Molina M. Costo-efectividad del uso de resonancia magnética Y radiografía convencional en pacientes Con pie diabético. Revista de Salud Pública 2010;12:974-81.

18. Chatterjee S, Riewpaiboon A, Piyauthakit P, et al. Cost of diabetes and its complications in Thailand: a complete picture of economic burden. Health Soc Care Community 2011;19:289-98.

19. World Health Organization IBfR, Bank aDTW. Tracking universal health coverage: 2017 global monitoring report. World Health Organization, 2017.
20. Chow CK, Ramasundarahettige $\mathrm{C}, \mathrm{Hu}$ W, et al. Availability and affordability of essential medicines for diabetes across high-income, middle-income, and low-income countries: a prospective epidemiological study. Lancet Diabetes Endocrinol 2018;6:798-808.

21. Wirtz VJ, Turpin K, Laing RO, et al. Access to medicines for asthma, diabetes and hypertension in eight counties of Kenya. Trop Med Int Health 2018;23:879-85.

22. Pagano E, Brunetti M, Tediosi F, et al. Costs of diabetes. Pharmacoeconomics 1999:15:583-95.

23. Larg A, Moss JR. Cost-of-illness studies. Pharmacoeconomics 2011;29:653-71.

24. Larson BA, Bii M, Halim N, et al. Incremental treatment costs for HIVinfected women initiating antiretroviral therapy during pregnancy: a 24-month micro-costing cohort study for a maternal and child health clinic in Kenya. PLoS One 2018;13:e0200199.

25. Scott CA, lyer HS, McCoy K, et al. Retention in care, resource utilization, and costs for adults receiving antiretroviral therapy in Zambia: a retrospective cohort study. BMC Public Health 2014;14.

26. Bommer C, Sagalova V, Heesemann E, et al. Global economic burden of diabetes in adults: projections from 2015 to 2030. Diabetes Care 2018;41:963-70.

27. International Diabetes Federation. IDF diabetes atlas. 8th edn Brussels, Belgium: International Diabetes Federation, 2017.

28. Shrestha N, Lohani SP, Angdembe MR, et al. Cost of diabetes mellitus care among patients attending selected outpatient clinics. JNMA J Nepal Med Assoc 2013;52:343-8.

29. Bermudez-Tamayo C, Besançon S, Johri M, et al. Direct and indirect costs of diabetes mellitus in Mali: a case-control study. PLoS One 2017; 12:e0176128.

30. Skordis-Worrall J, Round J, Arnold M, et al. Addressing the doubleburden of diabetes and tuberculosis: lessons from Kyrgyzstan. Global Health 2017;13

31. Tharkar S, Devarajan A, Kumpatla S, et al. The socioeconomics of diabetes from a developing country: a population based cost of illness study. Diabetes Res Clin Pract 2010;89:334-40.

32. Kumpatla S, Kothandan $\mathrm{H}$, Tharkar S, et al. The costs of treating long-term diabetic complications in a developing country: a study from India. J Assoc Physicians India 2013;61.

33. Chandra P, Gogate B, Gogate P, et al. Economic burden of diabetes in urban Indians. Open Ophthalmol J 2014;8:91-4.

34. Katam KK, Bhatia V, Dabadghao P, et al. High direct costs of medical care in patients with type 1 diabetes attending a referral clinic in a government-funded hospital in northern India. Natl Med J India 2016;29:64-7.

35. Tin ST, Iro G, Gadabu E, et al. Counting the cost of diabetes in the Solomon Islands and Nauru. PLoS One 2015;10:e0145603.

36. Javanbakht M, Baradaran HR, Mashayekhi A, et al. Cost-ofillness analysis of type 2 diabetes mellitus in Iran. PLoS One 2011;6:e26864

37. Yang W, Zhao W, Xiao J, et al. Medical care and payment for diabetes in China: enormous threat and great opportunity. PLoS One 2012; 7:e39513

38. Le C, Lin L, Jun D, et al. The economic burden of type 2 diabetes mellitus in rural Southwest China. Int J Cardiol 2013;165:273-7.

39. Chereches RM, Litan CM, Zlati AM, et al. Does co-morbid depression impact diabetes related costs? Evidence from a crosssectional survey in a low-income country. J Ment Health Policy Econ 2012;15:127-38.

40. Afroz A, Chowdhury HA, Shahjahan M, et al. Association of good glycemic control and cost of diabetes care: experience from a tertiary care hospital in Bangladesh. Diabetes Res Clin Pract 2016;120:142-8.

41. Aghili R, Khamseh ME, Malek M, et al. Structured self monitoring of blood glucose in Iranian people with type 2 diabetes; a cost consequence analysis. Daru 2012;20.

42. Riewpaiboon A, Chatterjee S, Piyauthakit P. Cost analysis for efficient management: diabetes treatment at a public district hospital in Thailand. Int J Pharm Pract 2011;19:342-9.

43. He M, Ma J, Wang D, et al. Costs for hospitalized patients with diabetes mellitus in China. Asia Pac J Public Health 2015;27:NP925NP935.

44. Bao X, Yang C, Fang K, et al. Hospitalization costs and complications in hospitalized patients with type 2 diabetes mellitus in Beijing, China. J Diabetes 2017;9.

45. Garcia AL, Villarreal RE, Galicia RL, et al. The cost of polypharmacy in patients with type 2 diabetes mellitus]. Revista Médica de Chile 2015;143:606-11.

46. de León-Castañeda CD, Altagracia-Martínez M, Kravzov-Jinich J, et al. Cost-effectiveness study of oral hypoglycemic agents in the treatment of outpatients with type 2 diabetes attending a public 
primary care clinic in Mexico City. ClinicoEconomics and Outcomes Research 2012;4.

47. Codogno JS, Fernandes RA, Sarti FM, et al. The burden of physical activity on type 2 diabetes public healthcare expenditures among adults: a retrospective study. BMC Public Health 2011;11.

48. Cobas RA, Ferraz MB, Matheus ASdeM, et al. The cost of type 1 diabetes: a nationwide multicentre study in Brazil. Bull World Health Organ 2013;91:434-40.

49. Celik A, Asci M, Celik BO, et al. The impact of laparoscopic diverted sleeve gastrectomy with ileal transposition (DSIT) on short term diabetic medication costs. Springerplus 2015;4.

50. González L, Elgart JF, Calvo H, et al. Changes in quality of care and costs induced by implementation of a diabetes program in a social security entity of Argentina. Clinicoecon Outcomes Res 2013;5:337-45.

51. Akari S, Mateti UV, Kunduru BR. Health-care cost of diabetes in South India: a cost of illness study. J Res Pharm Pract 2013;2:114-7.

52. Fadare J, Olamoyegun M, Gbadegesin BA. Medication adherence and direct treatment cost among diabetes patients attending a tertiary healthcare facility in Ogbomosho, Nigeria. Malawi Med $J$ 2015;27:65-70.

53. Wang W, Fu CW, Pan CY, et al. How do type 2 diabetes mellitusrelated chronic complications impact direct medical cost in four major cities of urban China? Value Health 2009;12:923-9.

54. Bahia LR, Araujo DV, Schaan BD, et al. The costs of type 2 diabetes mellitus outpatient care in the Brazilian public health system. Value Health 2011;14:S137-S140.

55. Borges NB, Ferraz MB, Chacra AR. The cost of type 2 diabetes in Brazil: evaluation of a diabetes care center in the city of São Paulo, Brazil. Diabetol Metab Syndr 2014;6.

56. Elgart JF, Asteazarán S, De La Fuente JL, et al. Direct and indirect costs associated to type 2 diabetes and its complications measured in a social security institution of Argentina. Int $J$ Public Health 2014;59:851-7.

57. Flessa S, Zembok A. Costing of diabetes mellitus type II in Cambodia. Health Econ Rev 2014;4.

58. Sosale B, Sosale A, Bhattacharyya A. Clinical effectiveness and impact on insulin therapy cost after addition of dapagliflozin to patients with uncontrolled type 2 diabetes. Diabetes Ther 2016;7:765-76.
59. Davari M, Boroumand Z, Amini M, et al. The direct medical costs of outpatient cares of type 2 diabetes in Iran: a retrospective study. Int J Prev Med 2016;7.

60. Farshchi A, Aghili R, Oskuee M, et al. Biphasic insulin aspart 30 vs. NPH plus regular human insulin in type 2 diabetes patients; a cost-effectiveness study. BMC Endocr Disord 2016;16.

61. Al-Sharayri MG, Alsabrah TM, Aljbori TM, et al. Insulin vials vs. insulin cartridges: further cost considerations. Saudi Pharm J 2013;21:225-7.

62. Hyassat $\mathrm{D}, \mathrm{Al}$ Shekarchi $\mathrm{N}$, Jaddou $\mathrm{H}$, et al. Are insulin analogues an unavoidable necessity for the treatment of type 2 diabetes in developing countries? The case of Jordan. East Mediterr Health $J$ 2015;21:729-35.

63. Biorac N, Jakovljević M, Stefanović D, et al. [Assessment of diabetes mellitus type 2 treatment costs in the Republic of Serbia]. Vojnosanit Pregl 2009;66:271-6.

64. Petkova E, Petkova V, Konstantinova M, et al. Economic evaluation of continuous subcutaneous insulin infusion for children with diabetes - a pilot study: CSII application for children economic evaluation. BMC Pediatr 2013;13.

65. Huang $Y$, Vemer $P$, Zhu J, et al. Economic burden in Chinese patients with diabetes mellitus using electronic insurance claims data. PLoS One 2016;11:e0159297.

66. Borges AP, Guidoni CM, Freitas O, et al. Economic evaluation of outpatients with type 2 diabetes mellitus assisted by a pharmaceutical care service. Arq Bras Endocrinol Metabol 2011;55:686-91.

67. Beran D, Higuchi M. Delivering diabetes care in the Philippines and Vietnam: policy and Practice Issues. Asia Pac J Public Health 2013;25:92-101

68. Gu S, Mu Y, Zhai S, et al. Cost-effectiveness of dapagliflozin versus acarbose as a monotherapy in type 2 diabetes in China. PLoS One 2016;11:e0165629.

69. Gu S, Deng J, Shi L, et al. Cost-effectiveness of saxagliptin vs glimepiride as a second-line therapy added to metformin in type 2 diabetes in China. J Med Econ 2015;18:808-20.

70. Elgart JF, González L, Rucci E, et al. Self-monitoring of blood glucose: use, frequency drivers, and cost in Argentina. J Diabetes Sci Technol 2014;8:1121-5. 